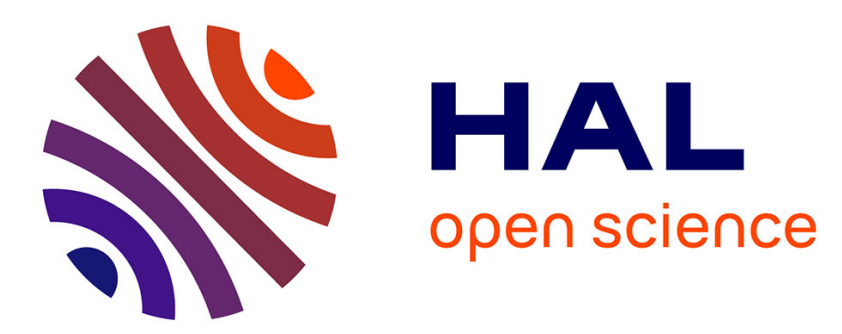

\title{
Quasi-automatic 3D reconstruction of the full spine from low-dose biplanar X-rays based on statistical inferences and image analysis
}

Laurent Gajny, Shahin Ebrahimi, Claudio Vergari, Elsa Angelini, Wafa Skalli

\section{- To cite this version:}

Laurent Gajny, Shahin Ebrahimi, Claudio Vergari, Elsa Angelini, Wafa Skalli. Quasi-automatic 3D reconstruction of the full spine from low-dose biplanar X-rays based on statistical inferences and image analysis. European Spine Journal, 2018, 28 (4), pp.658-664. hal-02181752

\section{HAL Id: hal-02181752 \\ https://hal.science/hal-02181752}

Submitted on 12 Jul 2019

HAL is a multi-disciplinary open access archive for the deposit and dissemination of scientific research documents, whether they are published or not. The documents may come from teaching and research institutions in France or abroad, or from public or private research centers.
L'archive ouverte pluridisciplinaire HAL, est destinée au dépôt et à la diffusion de documents scientifiques de niveau recherche, publiés ou non, émanant des établissements d'enseignement et de recherche français ou étrangers, des laboratoires publics ou privés. 


\title{
Quasi-automatic 3D reconstruction of the full spine from low-dose biplanar $\mathrm{X}$-rays based statistical inferences and image analysis
}

\author{
Laurent Gajny $^{1, *}$, Shahin Ebrahimi ${ }^{1}$, Claudio Vergari ${ }^{1}$, Elsa Angelini $^{2,3}$, Wafa Skalli $^{1}$
}

\begin{abstract}
Purpose: To design a quasi-automated three-dimensional reconstruction method of the spine from biplanar X-rays as the daily used method in clinical routine is based on manual adjustments of a trained operator and the reconstruction time is more than 10 minutes per patient.
\end{abstract}

Methods: The proposed method of 3D reconstruction of the spine (C3-L5) relies first on a new manual input strategy designed to fit clinicians' skills. Then, a parametric model of the spine is computed using statistical inferences, image analysis techniques and fast manual rigid registration.

Results: An agreement study with the clinically used method on a cohort of 57 adolescent scoliotic subjects has shown that both methods have similar performance on vertebral body position and axial rotation (null bias in both cases and standard deviation of signed differences of $1 \mathrm{~mm}$ and $3.5^{\circ}$ around respectively). In average, the solution could be computed in less than 5 minutes of operator time, even for severe scoliosis.

Conclusions: The proposed method allows fast and accurate 3D reconstruction of the spine for wide clinical applications and represents a significant step toward full automatization of $3 \mathrm{D}$ reconstruction of the spine. Moreover, it is to the best of our knowledge the first method including also the cervical spine.

Keywords. Scoliosis, 3D reconstruction, statistical inferences, landmark detection, biplanar X-rays.

\footnotetext{
1 Arts et Métiers ParisTech, LBM/Institut de Biomécanique Humaine Georges Charpak, 151 bd de l'Hôpital 75013, Paris, France.

${ }^{2}$ Telecom ParisTech, Université Paris-Saclay, France

${ }^{3}$ ITMAT Data Science Group, NIHR Imperial BRC, Imperial College London, UK.

* Corresponding author: Laurent.GAJNY@ensam.eu
} 


\section{Introduction}

Pathologies of the spine such as adolescent idiopathic scoliosis (AIS) are threedimensional deformities that affect position and orientation of vertebrae in space [1]. Methods providing 3D reconstructions of the spine allow the quantitative assessment of the deformity, the objective assessment of treatment effect $[2,3]$, the detection of progressive scoliosis [4] and the surgical planning and simulation [5]. Moreover, the interest of considering these deformities from head to pelvis has been demonstrated $[6,7]$.

Computed tomography (CT) is considered a gold standard for 3D reconstructions, using various segmentation algorithms (see for instance [8]). However, these acquisitions cause high ionizing radiations exposure [9] and therefore they are not appropriate for children with repetitive follow up examinations. Furthermore, the patient lies in supine position which considerably affects the spine configuration [10]. Alternatively, biplanar X-rays systems providing frontal and lateral views at a lower radiation dose level and in weight-bearing position are increasingly used for spine imaging [11].

Semi-automated 3D reconstruction methods of the thoracolumbar spine from biplanar $\mathrm{X}$-rays have considerably evolved in the last decades, reducing the requested operator-time and improving accuracy. An original method relying on the manual identification of the spinal curve and a very few set of landmarks has been proposed in [12], allowing fast generation of a first solution for the 3D reconstruction using a statistical parametric model. After manual adjustments of anatomical features in the model, the 3D reconstruction allowed accurate clinical measurements. This method has been extensively validated for mild and severe scoliosis [13-15] and it is, to the best of our knowledge, the only one widely used both in research and in clinical routine. However, the main limitation regarding the clinical daily use is its operator-dependency. While endplate digitization is widely used for clinical parameters measurements (Cobb angle, kyphosis, lordosis), feedback from operators and radiology technicians is that manual adjustments of the 3D model remain an issue in daily routine.

Other similar approaches based on reduced digitalized information and statistical models have been developed $[16,17]$. Further approaches are aiming to design quasi or fully automatic method based on artificial intelligence $[18,19]$. However, these studies are limited to thoracolumbar spine and pelvis while global analysis appears essential to investigate compensatory adaptations not only at the pelvis level $[20,21]$ but also at the cervical level $[6$, 22].

The aim of the present study was to develop a quasi-automatic 3D reconstruction method of the spine, from cervical spine to pelvis, reliable and sufficiently fast to be compatible with clinical daily practice. The manual input of the proposed method was designed to be closer to the type of radiographic measurements routinely performed by clinicians, such as Cobb and sagittal angles.

\section{Materials and methods}

\section{Database}

228 asymptomatic and AIS patients were retrospectively included in the present study. 171 of them (age range: 6-72 years old) were included in the training group for the statistical model, including 106 asymptomatic patients, 21 moderate AIS scoliotic patients 
(Cobb range: $\left.14^{\circ}-29^{\circ}\right)$ and 44 severe scoliotic patients (Cobb range: $31^{\circ}$ $\left.-93^{\circ}\right)$. On the other hand, 57 patients were included in the validation process (Table 1). All patients underwent low-dose biplanar X-Rays (EOS system, EOS Imaging, Paris, France).
Table 1 Description of the in vivo testing database.

\begin{tabular}{lccc}
\hline Agreement & N & \multicolumn{1}{l}{$\begin{array}{l}\text { Age } \\
\text { mean [min max] }\end{array}$} & $\begin{array}{l}\text { Cobb mean [min max] } \\
\text { [m }\end{array}$ \\
\hline $\begin{array}{l}\text { Scoliotic with Cobb } \\
\text { angles } \leq 30^{\circ}\end{array}$ & 41 & $13[10-15]$ & $18^{\circ}\left[10^{\circ}-29^{\circ}\right]$ \\
$\begin{array}{l}\text { Scoliotic with Cobb } \\
\text { angles }>30^{\circ}\end{array}$ & 16 & $14[10-17]$ & $49^{\circ}\left[33^{\circ}-63^{\circ}\right]$
\end{tabular}

Full 3D reconstructions integrating the lower cervical and thoracolumbar spine were performed for all patients by experienced operators using the previous method [12] and an extension of it for cervical spine reconstruction (C3 to C7) [23]. For each subject of the training database, a set of parameters already described in [12] was calculated, to which vertebral endplates orientations were added. Patient inclusions were validated by the Ethical committee (C.P.P. Ile de France VI).

A previously described in vitro database of dry thoracic and lumbar vertebrae were scanned with CT or physical contact measurement to obtain their 3D geometry [12]. Abnormal vertebrae were excluded, and the database was completed by 27 cervical spines. In total, 1285 vertebrae were measured.

\section{Manual identifications by a trained user}

\begin{abstract}
The user mainly digitalized vertebral endplates on traditional $2 \mathrm{D}$ views (Fig.1). On the sagittal view, the operator identified the upper endplate of $\mathrm{C7}$, the lower endplate of $\mathrm{T} 12$ and the sacral endplate. On the frontal view, the operator identified the sacral endplate, helped by a tool displaying the epipolar lines. According to the spinal deformity in the frontal plane, the operator also digitalized endplates corresponding to the 2D Cobb angles (two endplates for a single curvature and three for a double curve). In addition, the operator was asked to identify the odontoid and the acetabula on both
\end{abstract}

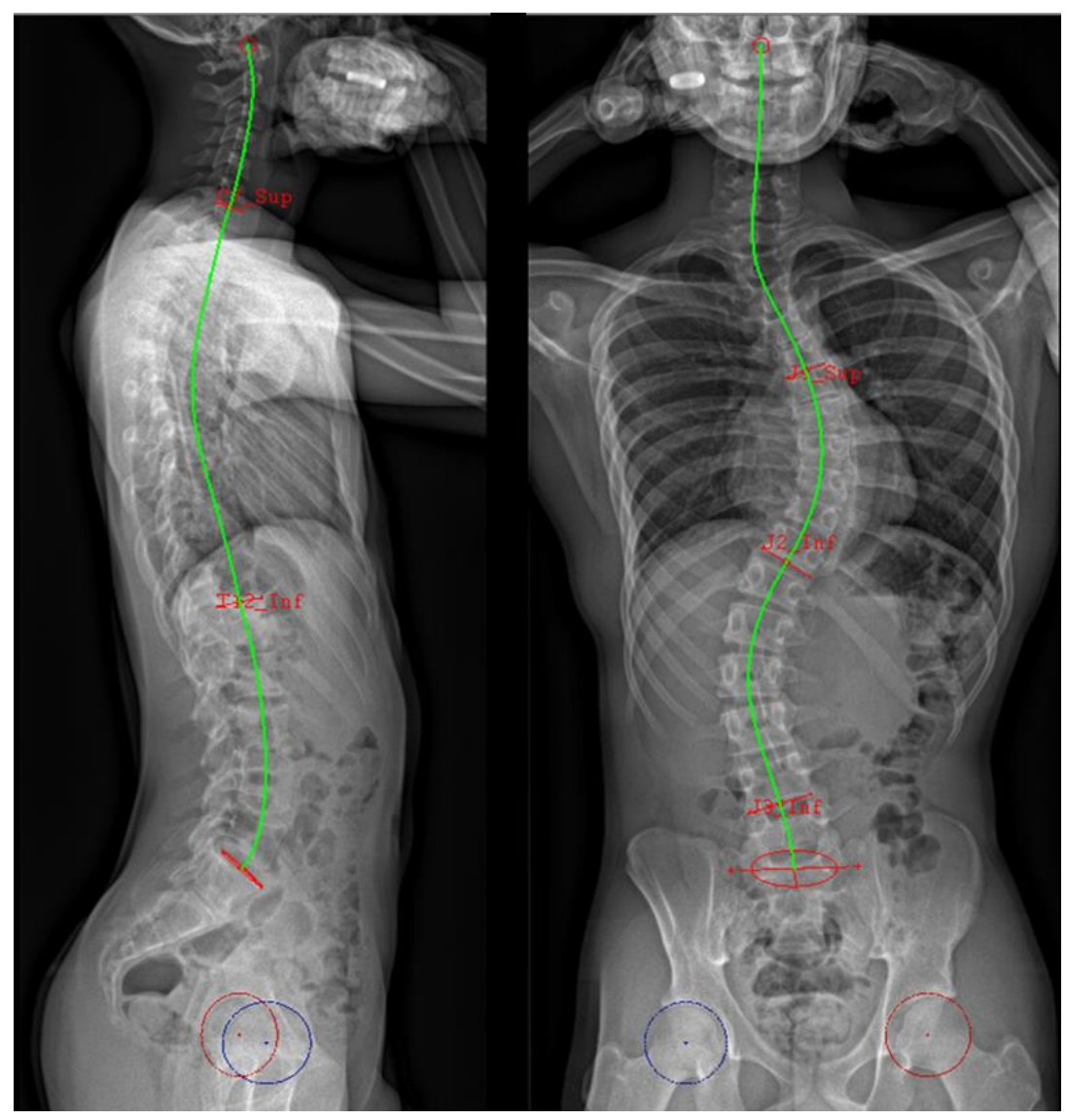

Figure 1. Manual identifications. 
views. Based on these identifications, an interactive spinal midline was provided to the user, who could adjust it on both views to make it pass through the centres of all vertebral endplates.

\section{Estimation of the vertebrae position and orientation}

From these two 2D curves, a 3D curve was reconstructed to approximate the spinal midline from the sacrum to the odontoid. The longitudinal inferences previously described in [12] have been adapted to estimate the positions of all vertebral endplates along the 3D spinal curve, their depth, width and orientations, thanks to the previously digitized endplates. The manually identified data were used as predictive parameters to determine the whole set of parameters using the $a$ priori knowledge provided by the in vivo training database and

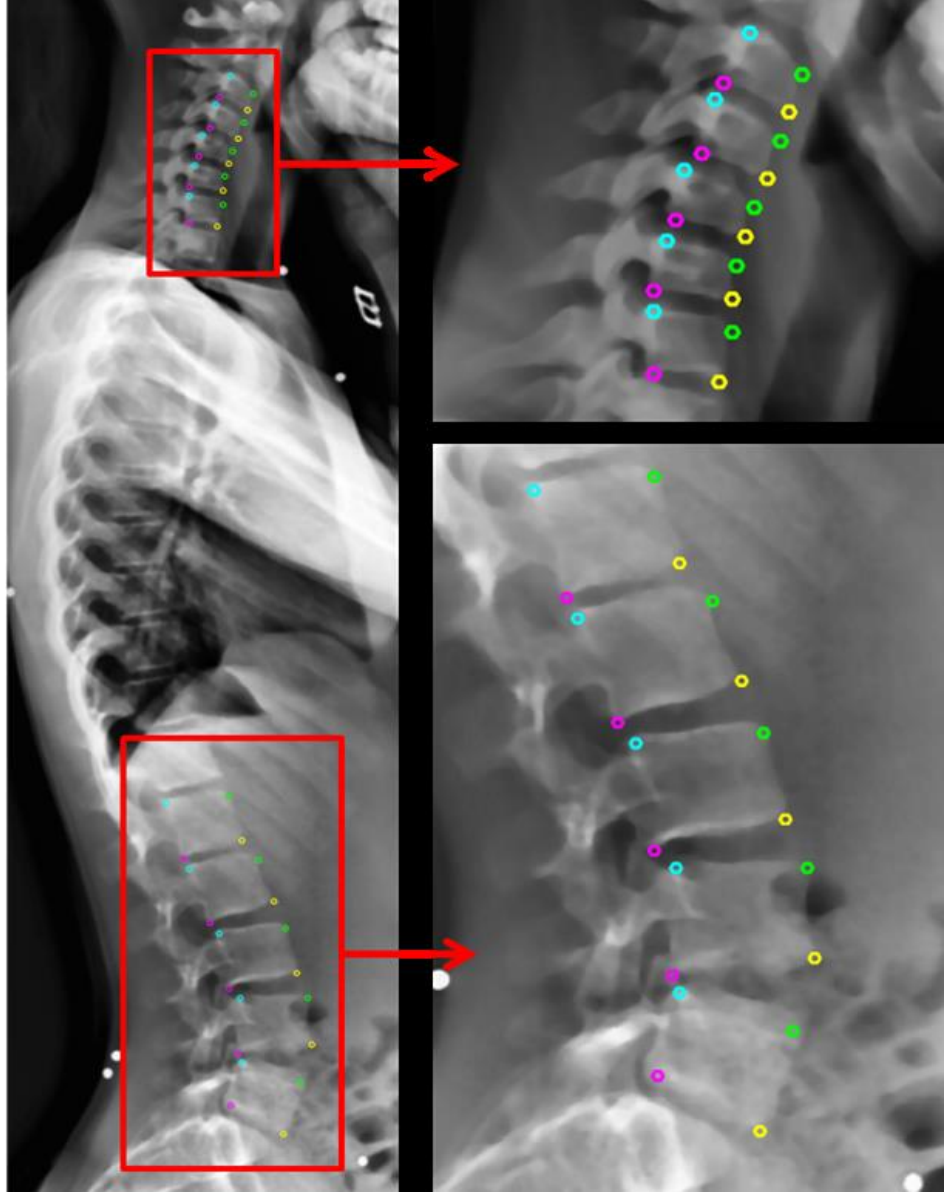

Figure 2. Automatic corner detection using the method presented in [25].

Gaussian process regression [24].

The regression method is iterative and it self-improves the model as the algorithm automatically decides to which vertebrae the digitalized endplates belong to. Moreover, lumbar and cervical vertebral corners and visible thoracic endplates were detected automatically and accurately using image processing [25] and machine learning (see Fig.2). The obtained pieces of information enabled to compute new predictors that again improved the model. At the end of this process, a simplified parametric model of the spine consisting of ellipses representing the endplates was computed.

\section{Estimation of the vertebrae shape}

For each vertebra, transversal inferences from the in vitro database were used to estimate the 3D geometrical vertebral shape. The method previously proposed in [12] has been adapted to take the lower cervical spine into account. Finally, the operator had the opportunity to refine the model through manual rigid registration of the vertebrae. An example of final output of this reconstruction method is illustrated in Fig.3.

\section{Evaluation}

Reconstructions obtained by the presented algorithm were compared to the ones obtained with the previous method [12] on the testing set of 57 AIS patients. For each vertebra of each reconstruction, a vertebral frame was computed. Hence vertebrae positions and orientations could be compared. Table 2 summarizes the signed mean errors and standard deviations (SD) 

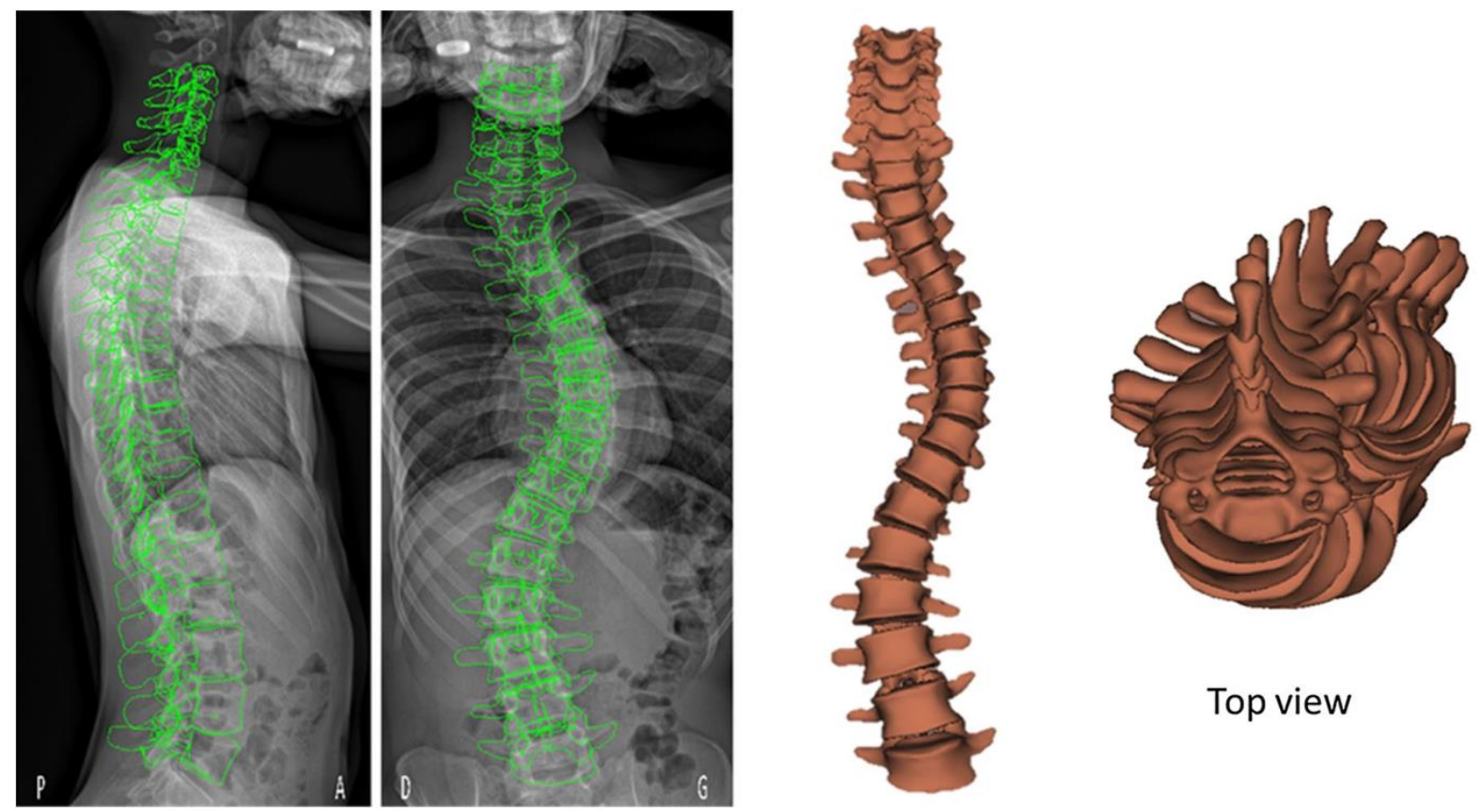

Top view

Figure 3. 3D reconstruction of the spine: retroprojection on the radiographs and 3D output.

of vertebrae position ( $\mathrm{x}$ - antero-posterior, $\mathrm{y}$ - lateral, $\mathrm{z}$ - vertical) and orientations (lateral, sagittal, axial). Agreement on spine clinical indices (Cobb angle, axial vertebral rotation at the apex (AVR), T1T12 kyphosis, L1L5 and L1S1 lordosis) and pelvic parameters (pelvic tilt, pelvic incidence and sacral slope) was also considered (Table 3 and Table 4 respectively).

\section{Results}

Mean signed differences of vertebral position between the proposed method and the previous one were lower than $1 \mathrm{~mm}$ in all directions, in all vertebral level and irrespectively of scoliosis severity (Table 2). Standard deviations were lower than $1.6 \mathrm{~mm}$ and $30 \%$ of them were lower than $1 \mathrm{~mm}$.

Most of the mean signed orientation differences (78\%) were lower than $1^{\circ}$ and the remaining ones - which are the mean signed sagittal orientation differences - were lower than $2^{\circ}$. Standard deviations were mostly lower than $4^{\circ}$ and only one exceeded $5^{\circ}$ (axial rotation at the thoracic level for severe scoliotic subjects).

Mean differences on spine clinical parameters, described in table 3, were limited to $1^{\circ}$ except for the Cobb angle (lower than $3^{\circ}$ ) and L1L5 lordosis. Standard deviations were lower than $6^{\circ}$ and in particular lower than $3^{\circ}$ for the L1S1 lordosis. Fig.4 shows a Bland-Altman graph for the agreement between the reference and the proposed method for axial vertebral rotation of the apical vertebra.

A similar table is provided for pelvic parameters (Table 4). For all of them, mean differences were no higher than a degree and standard deviation were not exceeding $2^{\circ}$.

Table 5 reports the mean absolute differences (and standard deviations) of vertebral positions and orientation between the current and previous methods, as well as a comparison with a recently published 3D reconstruction algorithm [19] on a cohort of severe scoliotic patients. While the testing datasets were different, mean Cobb angles were similar: $49^{\circ}$ in this study 
Table 2 Evaluation of the agreement between the proposed method and [12] with signed differences (mean \pm SD) for position (X: anteroposterior, Y: lateral, Z: vertical) and orientation (L: lateral, S: sagittal, A: axial).

\begin{tabular}{|c|c|c|c|c|c|c|}
\hline Cobb $\leq 30^{\circ}$ & $X(\mathrm{~mm})$ & $Y(\mathrm{~mm})$ & $\mathrm{Z}(\mathrm{mm})$ & $L\left({ }^{\circ}\right)$ & $S\left({ }^{\circ}\right)$ & $A\left({ }^{\circ}\right)$ \\
\hline Cervical & $0.5 \pm 0.4$ & $-0.0 \pm 1.7$ & $-0.1 \pm 0.6$ & $-0.1 \pm 3.8$ & $-1.6 \pm 4.2$ & $0.7 \pm 2.1$ \\
\hline Thoracic & $0.4 \pm 1.1$ & $0.0 \pm 1.1$ & $0.1 \pm 1.1$ & $0.0 \pm 2.9$ & $0.4 \pm 2.9$ & $0.1 \pm 3.7$ \\
\hline Lumbar & $0.9 \pm 0.8$ & $0.7 \pm 1.2$ & $-0.5 \pm 0.9$ & $0.3 \pm 3.9$ & $1.9 \pm 3.3$ & $0.3 \pm 2.8$ \\
\hline Cobb $>30^{\circ}$ & $X(\mathrm{~mm})$ & $Y(\mathrm{~mm})$ & $\mathrm{Z}(\mathrm{mm})$ & $L\left({ }^{\circ}\right)$ & $S\left({ }^{\circ}\right)$ & $A\left({ }^{\circ}\right)$ \\
\hline Cervical & $0.6 \pm 0.5$ & $0.0 \pm 1.4$ & $0.1 \pm 0.7$ & $-0.1 \pm 3.9$ & $-1.3 \pm 3.8$ & $0.5 \pm 2.7$ \\
\hline Thoracic & $0.2 \pm 1.5$ & $0.2 \pm 1.6$ & $0.3 \pm 1.4$ & $-0.5 \pm 3.3$ & $-0.3 \pm 3.5$ & $0.4 \pm 5.5$ \\
\hline Lumbar & $0.6 \pm 1.0$ & $0.2 \pm 1.6$ & $-0.6 \pm 1.4$ & $0.7 \pm 4.8$ & $2.0 \pm 4.6$ & $0.4 \pm 4.2$ \\
\hline All & $X(\mathrm{~mm})$ & $Y(\mathrm{~mm})$ & $\mathrm{Z}(\mathrm{mm})$ & $L\left(\left(^{\circ}\right)\right.$ & $S\left({ }^{\circ}\right)$ & $A\left({ }^{\circ}\right)$ \\
\hline Cervical & $0.5 \pm 0.4$ & $-0.0 \pm 1.6$ & $-0.0 \pm 0.6$ & $-0.2 \pm 3.9$ & $-1.5 \pm 4.1$ & $0.7 \pm 2.3$ \\
\hline Thoracic & $0.3 \pm 1.2$ & $0.1 \pm 1.3$ & $0.2 \pm 1.2$ & $-0.1 \pm 3.1$ & $0.3 \pm 3.1$ & $0.0 \pm 4.2$ \\
\hline Lumbar & $0.8 \pm 0.9$ & $0.3 \pm 1.3$ & $-0.5 \pm 1.0$ & $0.4 \pm 4.2$ & $2.0 \pm 3.7$ & $0.3 \pm 3.2$ \\
\hline All & $0.5 \pm 1.0$ & $0.1 \pm 1.4$ & $-0.0 \pm 1.1$ & $-0.0 \pm 3.5$ & $0.3 \pm 3.7$ & $0.2 \pm 3.7$ \\
\hline
\end{tabular}

and $45^{\circ}$ in [19]. With our approach, mean differences were globally similar but smaller than this alternative method, apart from lateral and sagittal vertebral orientations (and consequently, kyphosis and lordosis) where the difference between the two methods did not exceed $1^{\circ}$. Moreover, standard deviations of the differences were systematically lower - of more than $1 \mathrm{~mm}$ for position measurements and between $0.8^{\circ}$ and $3.2^{\circ}$ for angle measurements - with the proposed approach, yielding to lower maximal differences and more reliable reconstructions.

\section{Discussion and conclusion}

Scientific and clinical value of $3 \mathrm{D}$ reconstruction of the spine from biplanar X-ray is increasingly confirmed, but complexity and operator dependency of the currently used method in clinical routine is a real limitation to its systematic use. Through a more intuitive initialization process, a combination of automatic and soft manual adjustments, a quasiautomatic method for 3D reconstruction of the spine from biplanar radiographs has been proposed in this study. It is the first one to the best of our knowledge that also includes cervical vertebrae (C3 to $\mathrm{C} 7)$, which can be of great value to characterize compensation mechanisms.

The new identification method was based on standard radiographic identifications. Indeed, orthopaedic surgeons routinely identify junctional vertebrae on frontal radiographs. Moreover, identifications required on the sagittal view are very similar to classical 2D 
measurements of thoracic kyphosis and lumbar lordosis. A possible improvement of the method is the full automation of the spinal line adjustment, as it can be challenging for severe scoliosis. When vertebrae are axially rotated, the user has to check that the spinal midline passes through the centre of vertebra endplates and modify it accordingly. Nonetheless, this identification process was ergonomic and not time-consuming. Indeed, it took less than 2 min 30 per patient (depending on the scoliosis severity) for a trained user.

The automated adjustments proposed in this work - based on statistical inferences, image processing and machine learning - limit the tedious work of adjusting each vertebra manually via elastic deformation. When dealing with scoliotic patients, this step

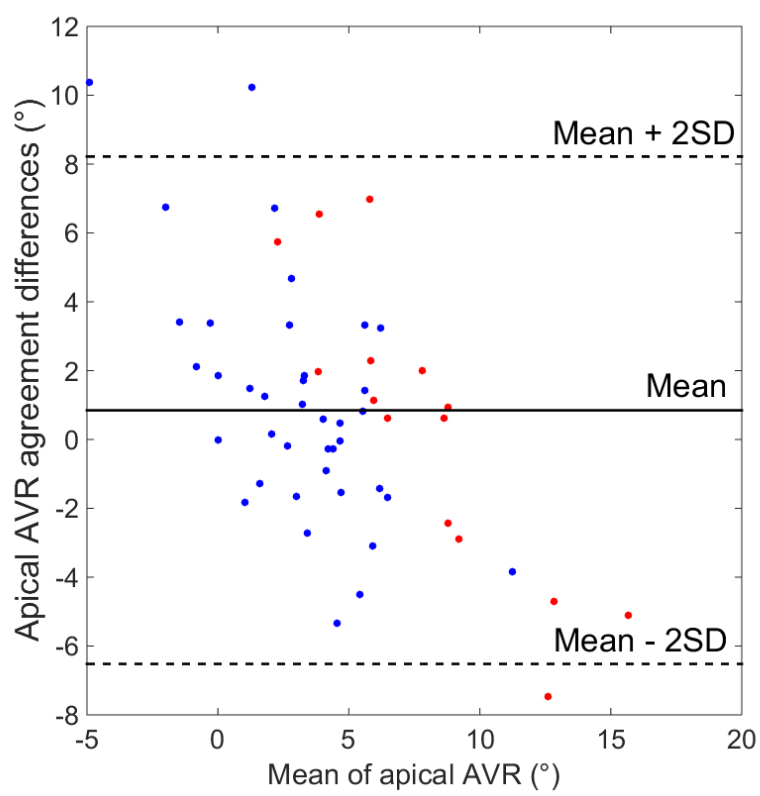

Figure 4. Bland-Altman plot for the agreement between the method [12] and the proposed method for axial vertebral rotation of the apical vertebra. required in the method of [12] took in average more than 10 minutes for a well-trained user. In the proposed method, faster manual adjustments of the model were possible by rigidly translating and rotating the vertebrae, when necessary. This process took between $1 \mathrm{~min} 30$ and $2 \mathrm{~min} 30$ depending on the scoliosis severity. Therefore, in total, the reconstruction process took less than $5 \mathrm{~min}$ per patient, even for severe scoliosis

The training database was voluntarily constituted of a wide variety of spine morphologies and patient ages. Indeed, the parametric spine representation - taking into account the spinal line curvature, its developed length and some vertebrae dimensions - allows the longitudinal inference model to easily identify whether the patient is young and scoliotic, adult and asymptomatic or every other combination. While this study focused on AIS patients, our method could be then used for a larger population.

Overall, the level of agreement for position between the present method and the previous one [12] was close to the uncertainty range of the latter. Further work should focus on improving the vertebral body and endplates orientation accuracy, although the level of agreement for apical vertebrae axial rotation was close to the uncertainty range documented in [13] for severe scoliosis, which was $6.5^{\circ}$. In this article, the essential pelvic parameters were

Table 3. Evaluation of the agreement between the proposed method and [12] with signed differences (mean \pm SD) for spinal clinical parameters.

\begin{tabular}{lccccc}
\hline & Cobb $\left({ }^{\circ}\right)$ & $\begin{array}{c}\text { AVR apex } \\
\left({ }^{\circ}\right)\end{array}$ & $\begin{array}{c}\text { K }- \text { T1T12 } \\
\left({ }^{\circ}\right)\end{array}$ & L- L1L5 $\left({ }^{\circ}\right)$ & L-L1S1 $\left({ }^{\circ}\right)$ \\
\hline Cobb $\leq 30^{\circ}$ & $1.5 \pm 4.9$ & $1.0 \pm 3.5$ & $0.2 \pm 5.2$ & $-2.7 \pm 5.0$ & $0.4 \pm 2.8$ \\
Cobb $>\mathbf{3 0 ^ { \circ }}$ & $3.2 \pm 5.8$ & $0.4 \pm 4.3$ & $1.0 \pm 6.1$ & $-4.5 \pm 3.2$ & $0.1 \pm 2.9$ \\
All & $2.0 \pm 5.1$ & $0.8 \pm 3.6$ & $0.4 \pm 5.4$ & $-3.2 \pm 4.2$ & $0.3 \pm 2.8$
\end{tabular}


Table 5. Evaluation of the agreement between the proposed method and [12] on severe scoliotic patients using absolute differences (mean \pm SD). Comparison with the results obtained in [19].

\begin{tabular}{lcccccc}
\hline & $\mathbf{X}(\mathbf{m m})$ & $\mathbf{Y}(\mathbf{m m})$ & $\mathbf{Z}(\mathbf{m m})$ & $\mathbf{L}\left(^{\circ}\right)$ & $\mathbf{S}\left({ }^{\circ}\right)$ & $\mathbf{A}\left({ }^{\circ}\right)$ \\
\hline This study, Cobb $>30^{\circ}$ & $1.0 \pm \mathbf{0 . 9}$ & $1.2 \pm \mathbf{1 . 0}$ & $0.9 \pm \mathbf{0 . 9}$ & $2.8 \pm \mathbf{2 . 6}$ & $3.0 \pm \mathbf{2 . 7}$ & $3.5 \pm \mathbf{3 . 1}$ \\
{$[19]$, Cobb $>40^{\circ}$} & $1.5 \pm \mathbf{2 . 0}$ & $1.5 \pm \mathbf{2 . 0}$ & $1.4 \pm \mathbf{2 . 6}$ & $2.7 \pm \mathbf{3 . 5}$ & $2.6 \pm \mathbf{3 . 5}$ & $4.5 \pm \mathbf{5 . 8}$ \\
\hline & $\mathbf{C o b b}\left({ }^{\circ}\right)$ & $\mathbf{A V R}\left({ }^{\circ}\right)$ & $\begin{array}{c}\text { K-T1T12 } \\
\left({ }^{\circ}\right)\end{array}$ & $\begin{array}{c}\text { L- L1L5 } \\
\left({ }^{\circ}\right)\end{array}$ & & \\
\hline This study, Cobb $>30^{\circ}$ & $4.2 \pm \mathbf{5 . 0}$ & $3.4 \pm \mathbf{2 . 4}$ & $5.2 \pm \mathbf{3 . 2}$ & $4.9 \pm \mathbf{2 . 5}$ & \\
{$[19]$, Cobb $>40^{\circ}$} & $4.6 \pm \mathbf{6 . 0}$ & $5.1 \pm \mathbf{5 . 6}$ & $4.2 \pm \mathbf{4 . 9}$ & $4.2 \pm \mathbf{4 . 9}$ & &
\end{tabular}

also considered. As they are computed exactly like in the previous method based on the digitalization of pelvis landmarks [12], we have observed an agreement consistent with the reproducibility study performed in the same article (For moderate scoliosis, the authors reported an uncertainty of $1.4^{\circ}, 3.4^{\circ}$ and $3.0^{\circ}$ for pelvic tilt, pelvic incidence, and sacral slope respectively). Our approach also offered a better agreement to the previous method than the fully automatic approach described in [19] both for vertebrae position, orientation and clinical indices. While a fully automatic method is the target of further research, the proposed method combining automatic adjustments and soft manual intervention constitutes a trade-off between automation and accuracy. Moreover, it contributes to simplify the process of 3D reconstruction of the spine from head to pelvis. This is essential for a wider application of 3D analysis in clinical routine for diagnosis and treatment planning of scoliosis.

\section{Acknowledgments}

The authors thank the ParisTech BiomecAM chair program, on subject-specific musculoskeletal modelling and in particular Société Générale and COVEA. The authors would also like to thank Aurélien Laville for having initiated this work.

\section{Bibliography}

1. Stokes IA (1994) Three-dimensional terminology of spinal deformity. A report presented to the Scoliosis Research Society by the Scoliosis Research Society Working Group on 3-D terminology of spinal deformity. Spine 19:236-248

2. Ilharreborde B, Sebag G, Skalli W, Mazda K (2013) Adolescent idiopathic scoliosis treated with posteromedial translation: radiologic evaluation with a 3D low-dose system. Eur Spine J 22:2382-2391 . doi: 10.1007/s00586-013-2776-7

3. Illés T, Tunyogi-Csapó $M$, Somoskeöy $S$ (2011) Breakthrough in three-dimensional scoliosis diagnosis: significance of horizontal plane view and vertebra vectors. Eur Spine J Off Publ Eur Spine Soc Eur Spinal Deform Soc Eur Sect Cerv Spine Res Soc 20:135-143 . doi: 10.1007/s00586010-1566-8

4. Skalli W, Vergari C, Ebermeyer E, et al (2017) Early Detection of Progressive Adolescent Idiopathic Scoliosis: A Severity Index. Spine 42:823-830 . doi: 10.1097/BRS.0000000000001961

5. Lafon Y, Steib J-P, Skalli W (2010) Intraoperative three dimensional correction during in situ contouring surgery by using a numerical model. Spine 35:453-459 . doi: 10.1097/BRS.0b013e3181b8eaca 
6. Amabile C, Huec J-CL, Skalli W (2016) Invariance of head-pelvis alignment and compensatory mechanisms for asymptomatic adults older than 49 years. Eur Spine J 1-9 . doi: 10.1007/s00586-016-4830-8

7. Schwab F, Farcy J-P, Bridwell K, et al (2006) A clinical impact classification of scoliosis in the adult. Spine 31:2109-2114 . doi: 10.1097/01.brs.0000231725.38943.ab

8. Hanaoka S, Masutani $\mathrm{Y}$, Nemoto $\mathrm{M}$, et al (2017) Landmark-guided diffeomorphic demons algorithm and its application to automatic segmentation of the whole spine and pelvis in CT images. Int J Comput Assist Radiol Surg 12:413-430 . doi: 10.1007/s11548-016-1507-z

9. Brenner DJ, Hall EJ (2007) Computed tomography--an increasing source of radiation exposure. N Engl J Med 357:2277-2284 . doi: 10.1056/NEJMra072149

10. Yazici M, Acaroglu ER, Alanay A, et al (2001) Measurement of vertebral rotation in standing versus supine position in adolescent idiopathic scoliosis. J Pediatr Orthop 21:252-256

11. Dubousset J, Charpak G, Dorion I, et al (2005) A new 2D and 3D imaging approach to musculoskeletal physiology and pathology with low-dose radiation and the standing position: the EOS system. Bull Acad Natl Med 189:287-297; discussion 297-300

12. Humbert L, De Guise JA, Aubert B, et al (2009) 3D reconstruction of the spine from biplanar Xrays using parametric models based on transversal and longitudinal inferences. Med Eng Phys 31:681-687 . doi: 10.1016/j.medengphy.2009.01.003

13. Ilharreborde B, Steffen JS, Nectoux E, et al (2011) Angle measurement reproducibility using EOS three-dimensional reconstructions in adolescent idiopathic scoliosis treated by posterior instrumentation. Spine 36:E1306-1313 . doi: 10.1097/BRS.0b013e3182293548

14. Carreau JH, Bastrom T, Petcharaporn M, et al (2014) Computer-Generated, Three-Dimensional Spine Model From Biplanar Radiographs: A Validity Study in Idiopathic Scoliosis Curves Greater Than 50 Degrees. Spine Deform 2:81-88 . doi: 10.1016/j.jspd.2013.10.003

15. Ferrero E, Lafage $R$, Vira $S$, et al (2016) Three-dimensional reconstruction using stereoradiography for evaluating adult spinal deformity: a reproducibility study. Eur Spine J 1-9 . doi: 10.1007/s00586-016-4833-5

16. Kadoury S, Cheriet F, Labelle H (2009) Personalized X-Ray 3-D Reconstruction of the Scoliotic Spine From Hybrid Statistical and Image-Based Models. IEEE Trans Med Imaging 28:1422-1435. doi: 10.1109/TMI.2009.2016756

17. Moura DC, Barbosa JG (2014) Real-scale 3D models of the scoliotic spine from biplanar radiography without calibration objects. Comput Med Imaging Graph 38:580-585 . doi: 10.1016/j.compmedimag.2014.05.007

18. Lecron F, Boisvert J, Mahmoudi S, et al (2013) Three-dimensional spine model reconstruction using one-class SVM regularization. IEEE Trans Biomed Eng 60:3256-3264 . doi: 10.1109/TBME.2013.2272657

19. Aubert B, Vidal PA, Parent S, et al (2017) Convolutional Neural Network and In-Painting Techniques for the Automatic Assessment of Scoliotic Spine Surgery from Biplanar Radiographs. In: Medical Image Computing and Computer-Assisted Intervention - MICCAI 2017. Springer, Cham, pp 691-699

20. Barrey C, Jund J, Noseda O, Roussouly P (2007) Sagittal balance of the pelvis-spine complex and lumbar degenerative diseases. A comparative study about 85 cases. Eur Spine J Off Publ Eur Spine Soc Eur Spinal Deform Soc Eur Sect Cerv Spine Res Soc 16:1459-1467 . doi: 10.1007/s00586-006-0294-6 
21. Lafage V, Schwab F, Skalli W, et al (2008) Standing balance and sagittal plane spinal deformity: analysis of spinopelvic and gravity line parameters. Spine 33:1572-1578 . doi: 10.1097/BRS.0b013e31817886a2

22. Canavese F, Turcot K, De Rosa V, et al (2011) Cervical spine sagittal alignment variations following posterior spinal fusion and instrumentation for adolescent idiopathic scoliosis. Eur Spine J Off Publ Eur Spine Soc Eur Spinal Deform Soc Eur Sect Cerv Spine Res Soc 20:1141-1148 . doi: 10.1007/s00586-011-1837-z

23. Rousseau M, Laporte S, Chavary-bernier E, et al (2007) Reproducibility of Measuring the Shape and Three-dimensional Position of Cervical Vertebrae in Upright Position Using the Eos Stereoradiography System. Spine 32:2569-2572 . doi: 10.1097/BRS.0b013e318158cba2

24. Lüthi M, Gerig T, Jud C, Vetter T (2018) Gaussian Process Morphable Models. IEEE Trans Pattern Anal Mach Intell PP:1-1 . doi: 10.1109/TPAMI.2017.2739743

25. Ebrahimi S, Angelini E, Gajny L, Skalli W (2016) Lumbar spine posterior corner detection in Xrays using Haar-based features. In: 2016 IEEE 13th International Symposium on Biomedical Imaging (ISBI). pp 180-183 